\title{
Politica e Economia no Federalismo do Governo Geisel ${ }^{1}$
}

Politics and economy of federalism during the Geisel Government

FABIANA DA CUNHA SADDI*

RESUMO: O objetivo deste trabalho é estudar a dinâmica política da reconstrução do federalismo no Brasil durante o governo Geisel, no início da transição brasileira para a democracia. Essa análise começará em novembro de 1974, quando os resultados da eleição levaram o governo federal a começar a usar as relações econômicas e políticas do federalismo para conduzir e controlar dois projetos complementares: a liberalização política controlada e o Segundo Plano Brasileiro para o Desenvolvimento.

PALAVRAS-CHAVE: Federalismo; descentralização; transição política; política fiscal; II PND.

ABSTRACT: The aim of this work is to study the political dynamic of the reconstruction of federalism in Brazil during the Geisel Government, in the very beginning of the Brazilian transition to democracy. This analysis will begin in November 1974, when the results of the election moved the federal government to start using the economic and political relations of federalism to conduct and control two complementary projects: the controlled political liberalization and the Second Brazilian Plan for Development.

KEYWORDS: Federalism; decentralization; political transition; fiscal policy; II BPD.

JEL Classification: $\mathrm{H}$; H7; H77.

O tema do federalismo envolve duas problemáticas: uma prática e uma teórica. Esta se traduz na dificuldade de utilização dos instrumentos oferecidos seja pela ciência econômica, seja pela ciência política, na análise de distintos arranjos federativos no mundo. Essa problemática será aqui assinalada pelo fato de se pretender ir além dos modelos econômicos de finanças públicas - que dão extremada ênfase às regras fiscais que poderiam acarretar a oferta eficiente de bens públicos num arranjo federativo - e das análises políticas, as quais ou enfatizam excessivamen-

\footnotetext{
${ }^{1}$ Versão modificada do texto apresentado no V Encontro Nacional de Economia Política, de 20 a 23 de junho de 2000 em Fortaleza.

"Doutoranda em sociologia, Faculdade de Filosofia, Letras e Ciências Humanas da Universidade de São Paulo - FFLCH/USP, São Paulo/SP, Brasil. E-mail: fabianasaddi1@gmail.com.
} 
te o modelo do federalismo americano ou dão acentuada importância às regras político-institucionais que orientam o sistema político numa federação.

A problemática prática, por sua vez, refere-se à forma como fatores políticos e socioeconômicos se retroalimentam e se sobrepõem na vida real. Relaciona-se às incertezas, conflitos e constrições originados no decorrer do próprio processo político-econômico e, de forma mais acentuada, nos períodos em que se pretende efetuar mudanças nas relações de poder vigentes. Essa problemática será aqui assinalada ao se analisarem as relações federativas nos anos do governo Geisel.

O objetivo deste artigo é reconstruir as relações do federalismo brasileiro no princípio da distensão política e, mais precisamente, após as eleições de 1974. Essa reconstrução se dará mediante a análise e inter-relação das variáveis políticas e econômicas que se sobrepuseram e retroalimentaram as relações intergovernamentais no período do governo Geisel. Cabe firmar que a escolha desse par de medidas orientadoras das relações do federalismo, conceituadas ora na esfera da política, ora no âmbito da economia, baseia-se no fato de elas se revelarem, na prática, como um par conceitual que nos permite analisar a dinâmica política do processo na gênese da transição ${ }^{2}$ brasileira. De forma que se opta aqui por uma noção de federalismo que o compreende como relações sociais ${ }^{3}$ - logo relações políticas e econômicas - específicas entre as esferas de poder de uma federação. A questão federativa pode, assim, ser abordada como um processo político que requer a aquiescência parcial dos atores, porque envolve a constituição ou restituição de poderes transferidos de uma instância a outra. A hipótese deste trabalho é que as relações políticas e econômicas subjacentes ao federalismo foram utilizadas, nesse período, como instrumento de controle do processo que o Executivo pretendia dominar-legitimar.

É pelo fato de o Estado Brasileiro assumir a forma política de uma federação e, sobretudo, em razão de as elites políticas regionais terem desempenhado papel relevante desde a formação da Federação Brasileira que a questão do federalismo esteve sempre presente nas relações estatais ou latente a elas, mesmo no regime inaugurado em 1964. Esse regime foi caracterizado, desde a sua origem, pela manutenção de instituições representativas, juntamente com instituições de tipo autoritário. No entanto, é tão-somente a partir de 1974, quando o governo Geisel põe em prática seu projeto de liberalização política, que se verifica uma exacerbação do sistema de representação. De forma que uma das principais mudanças ocorridas no pós1975 assenta-se no fato de a "revalorização da Federação" ter se revelado na "forma mais adequada do Governo controlar o processo de institucionalização"

\footnotetext{
${ }^{2}$ O’Donnel e Schmitter (1988) definem transição como o intervalo entre um regime político e outro. Conforme estes autores, a transição apresenta duas fases: a de liberalização (também chamada na literatura de distensão, abertura ou descompressão), caracterizada pelo processo de efetivação de determinados direitos políticos e civis, e a de democratização, entendida como a extensão da cidadania e a mudança da institucionalidade preexistente à transição.

${ }^{3}$ As relações sociais serão tratadas conforme a formulação de Max Weber (1968).
} 
(Sallum Jr., 1996, p. 40), ao qual visava seu projeto político. Foi, portanto, como resposta ao inesperado resultado das eleições de novembro de 1974 que o governo federal (1) desacelerou o ritmo da implementação de mecanismos político-eleitorais de cunho liberalizante empregados desde a posse de Geisel e (2) passou a estabelecer alianças estratégicas com atores que pudessem apoiar a política do Governo Federal junto ao Congresso e a grupos econômicos.

Pretende-se, primeiramente, analisar algumas medidas políticas e econômicas norteadoras das relações do federalismo no governo Geisel. Será possível, posteriormente, assinalar traços específicos das ações do Estado Central, subjacentes às relações intergovernamentais. E, por fim, apontar uma característica própria das relações intergovernamentais na gênese da transição política brasileira: o "federalismo de impasse".

\section{AS RELAÇÕES POLÍTICAS DO FEDERALISMO APÓS 1974}

As "situações" 4 política e socioeconômica sinalavam desde 1973 a necessidade de se efetuar mudanças no regime político brasileiro. De forma que o governo Geisel, em 1974, pôs em prática uma estratégia de liberalização controlada, caracterizada primordialmente pela gradual e crescente valorização do processo político-eleitoral. No entanto, os resultados das eleições de 1974 obrigaram o governo a rever sua estratégia, no sentido de diminuir o ritmo com que as mudanças seriam efetuadas. Se o projeto Golbery-Geisel em si já acentuava a importância das eleições, o processo veio a corroborar ainda mais o acentuado papel a ser desempenhado pelas variáveis político-eleitorais no decorrer da abertura. Trata-se de variável chave na reconstrução da dinâmica da situação política em meio à qual se encontravam os estrategistas do governo. Uma vez que o processo político-eleitoral se traduz não apenas como variável essencial, mas também como elemento de incerteza que revelou os limites e os paradoxos da gênese da abertura, dado o impacto das consecutivas eleições no decorrer da distensão política, como assinalam Lamounier (1988) e Santos (1978), entre outros.

De forma que o governo Geisel iniciou o ano de 1975 em meio a uma "situação" de derrota eleitoral, de expectativa inflacionária e de conseqüentes conflitos dentro do setor militar. "Situação" essa que levou Geisel a tomar medidas que visassem a acentuar o controle da liberalização política. No que se refere às novas opções de estratégia, o Governo pretendeu acentuar sua política em relação à Arena, como peça de suporte político às medidas de controle. E, dessa forma, lançou mão da influência dos líderes políticos em toda a federação, os quais passaram a ter um papel significativamente importante no projeto do Governo.

\footnotetext{
${ }^{4}$ A “situação" “envolve a idéia de um complexo de ações reciprocamente referidas” (Cohn, 1979, p. 86), as quais atribuem sentido àquela situação. A duração de uma "situação", por exemplo, não pode ser determinada, já que ela depende de vários fatores socioculturais que não são objetivamente dados.
} 
Cabe lembrar que o desenvolvimento político precedente contribuiu para que se verificasse um processo de divisão dentro da Arena, de forma que a Arena não acabou se revelando de fato como o "Partido da Revolução". Esse distanciamento da Arena em relação aos anseios do governo federal também ocorreria em 1975, quando os conflitos entre os novos políticos da Arena no Legislativo apontavam que apenas de forma bem limitada a Arena poderia mostrar-se estrategicamente como instrumento de apoio político na realização do projeto do governo.

"A posse do novo Congresso inaugura uma fase marcada pela recomposição gradual do papel do Legislativo como 'forum de debate'" (Klein e Figueiredo, 1978,

p. 74). Esses debates demonstraram, por exemplo, o nível de fragmentação da Arena na ocasião das críticas dos senadores da oposição ao governo. Ademais, os conflitos desencadeados no âmbito da indicação dos presidentes da Câmara e do Senado por Geisel também contribuíram para agravar a divisão interna dentro do partido. Pois, apesar de o presidente da República ter escolhido políticos comprometidos com sua estratégia, os novos líderes da Câmara e do Senado não obtiveram margem de manobra suficiente para consolidar uma base de apoio ao governo federal dentro do Congresso Nacional. Com efeito, "uma vez mais a Arena falhara como base política para a implementação do projeto presidencial visando à institucionalização do regime" (Klein e Figueiredo, 1978, p. 75). Como ressalta Santos, um "equívoco estratégico consistiu na definição da Arena como partido da Revolução, o que implicitamente colocava o outro partido fora do número de competidores políticos legítimos" (Santos, 1978, p. 128).

Como resultado, o apoio político ao governo federal passou a ocorrer alhures e, mais especificamente, no âmbito dos governos estaduais. "Diante da omissão dos dirigentes arenistas no plano federal, processou-se movimentação visando à afirmação de novas alianças centradas em torno dos Executivos estaduais em condições de garantir apoio efetivo ao governo" (Klein e Figueiredo, 1978, p. 78). Essa movimentação pode ser exemplificada pela iniciativa dos governadores de São Paulo, Rio Grande do Sul e Minas Gerais - cujas indicações em 1974 foram fruto da sondagem partidária empreendida em várias regiões por Petrônio Portella - de unirem esforços a fim de apoiar a estratégia do governo federal, objetivando até mesmo utilizar suas bases políticas estaduais na viabilização do projeto político do governo.

De forma que foi mais precisamente a partir desse momento que as relações do federalismo passaram a se mostrar como instrumento predominante na estratégia de liberalização controlada. Apesar de os decisores do governo já reconhecerem o peso representado pelos líderes políticos regionais desde o período da sucessão presidencial, esses líderes só passaram a adquirir papel de relevo na estratégia política de Geisel a partir do momento em que se verificou a dificuldade de sustentação política ao governo no Congresso Nacional. A partir do momento em que não apenas os governadores tornaram público seu apoio, como também a ação do Estado já começava a direcionar-se para as relações do federalismo, seja no campo da política, seja no campo da economia. De forma que as decisões políticas e econômicas se complementaram, traduzindo-se em consecutivas variáveis que se inter-relacionaram e se retro- 
alimentaram e que, por isso, conformaram não apenas o processo do federalismo, como também o princípio da trajetória da transição brasileira.

De forma diferente do período militar anterior, quando "a nova federação, por um lado, reduziu o poder dos estados, logo das elites, e por outro, fez dos governantes estaduais executores de políticas públicas definidas no âmbito nacional" (Sallum Jr., p. 32), após 1974 e de modo mais acentuado após 1975, o governo Geisel passou a redirecionar sua estratégia em relação à federação, no intuito de não perder o controle do processo de distensão política (Klein e Figueiredo, 1978) (Abrucio,

1994) (Sallum Jr., 1996). A fim de dar continuidade a seu projeto, o governo alterou, portanto, as regras das instituições político-eleitorais, as quais visavam a criar condições institucionais para a formação de uma elite política civil que pudesse apoiar o regime.

Em 1976, na ocasião da primeira eleição após 1974, foi criada a Lei Falcão, em resposta aos mapas eleitorais produzidos pela agência central do SNI (Moreira Alves, 1984, p. 190). Apesar de a Lei Falcão objetivar limitar precisamente o uso do rádio e da televisão pela oposição, também acabou impactando o partido do governo. Como resultado, "a primeira metade de 1976 foi marcada, portanto, por crescente estremecimento das coalizões civil e militar que vinham dando suporte ao regime desde, pelo menos, 1968, e pela continuada incapacidade governamental de criar as condições para a constituição de novas coalizões de apoio, ${ }^{5}$ senão ao governo, minimamente à sua estratégia de reconversão democrática gradual" (Santos, 1978, p. 135). De forma que a partir dos efeitos desencadeados pela Lei Falcão, o governo também passou a lançar mão da patronagem não apenas no âmbito da política - no intuito mais imediato de vencer as próximas eleições municipais em 1976 - , mas também no campo da economia, como veremos mais adiante.

No campo político-institucional, essa nova estratégia de criar as condições para a constituição de novas coalizões de apoio se deu mediante a adoção de medidas consecutivas, adotadas não apenas em reação aos eventos anteriores a 1975, mas também como conseqüência do processo político subseqüente àquele período. Em virtude da derrota de 1974 e do posterior incremento do número de municípios sob o comando do MDB nas eleições de 1976, “o simples anúncio do pleito de 15 de novembro tornou-o uma eleição temida" (Britto, 1980, p. 7). "No curto prazo, pois, após os resultados de 1976 e antes das eleições de 1978, ou bem o governo abandona sua estratégia de normalização democrática, ou bem revê a tática que vem empregando para implementá-la" (Santos, 1978, p. 135-6). De forma que entre as eleições de 1976 e 1978 o governo federal adotou medidas político-institucionais que visavam a conter o grau de incerteza e de risco revelado pelo processo eleitoral até então. Pontualmente, o governo federal pretendia conter o avanço do MDB nos centros urbanos nas eleições a serem realizadas em 1978, quando ocorreriam eleições diretas para governador e senador.

\footnotetext{
${ }^{5}$ Grifo nosso.
} 
Como resultado, aproveitando o recesso parlamentar decretado pelo Ato Complementar $\mathrm{n}^{\circ} 102$, de $1^{\circ}$ de abril de 1977 , o governo federal resolveu criar mecanismos político-institucionais, mediante a Emenda Constitucional $n^{\circ} 8$, que visavam a capacitar o governo a dar continuidade ao seu projeto de distensão via controle eleitoral. Conforme o chamado "Pacote de Abril de 1977", mantinha-se a eleição indireta para governador em 1978 e adiavam-se as eleições diretas para 1982, alterava-se a regra para representação dos deputados na Câmara, instituía-se que 1/3 dos senadores seria eleito de modo indireto - os chamados "senadores biônicos" - e regulamentava-se que bastava a maioria absoluta dos votos do Congresso para a aprovação das emendas constitucionais. Demais, "alterou-se a composição do Colégio eleitoral destinado a escolher o Presidente da República em 1985, dando mais peso às maiorias políticas existentes nas assembléias estaduais, que se esperava continuassem vinculadas ao regime" (Sallum Jr., 1996, pp. 41-2), aumentou-se o mandato presidencial de cinco para seis anos para o próximo presidente e estendeu-se ainda a Lei Falcão para as eleições estaduais e federais.

Como conseqüência, o número de cadeiras de cada Estado na Câmara não seria calculado em proporção ao número de eleitores registrados em cada Estado, mas em proporção a sua população total. Dessa forma, "a nova lei aumentava a representação dos estados pobres do Norte e Nordeste, onde os índices de analfabetismo são muito altos e onde a Arena era mais forte" (Moreira Alves, 1984, p. 194). Foram ainda incrementados os números de estados aliados, mediante a subdivisão dos "estados pouco urbanizados e politicamente aliados, como Mato Grosso, em 1977 (Sallum Jr., 1996, p. 41).

Ademais, cumpre assinalar ainda que o "Pacote de Abril de 1977" também "foi, claramente, uma tentativa de realinhamento das forças políticas em função de um projeto de abertura acoplado à decisão de seguir adiante na substituição de importações" (Dias e Aguirre, 1992, p. 89). De forma que, como apontado também por Medeiros e Abrucio, a patronagem realizada pelo governo federal não se verificava apenas no âmbito político-eleitoral, mas também foi revelada pelas constrições que influenciaram o financiamento federal na década seguinte. O lado político da patronagem se complementava na sua face econômica, mais especificamente no que se refere à articulação com estados e municípios, à estratégia de redirecionamento dos investimentos e à estratégia da distribuição da renda subjacentes ao II PND, isto é, no que tange à forma mediante a qual o Estado federal canalizou os recursos econômicos na Federação ao implementar o II PND, como veremos mais adiante.

O "Pacote de Abril", portanto, "mostrou sua importância ao garantir para Geisel maior controle sobre o 'público interno' e proporcionar-lhe fôlego para as reformas políticas futuras, mas estas viriam como mais uma política autoritária: sem a participação efetiva dos representante das sociedade no sistema político" (Mathias, 1995, p. 122). Como reação ao "Pacote de Abril", o MDB, por exemplo, tornouse de fato um partido de oposição ao governo, uma vez que assinalava sempre as contradições entre as medidas de controle político e a intenção de liberalizar a política. Um dos paradoxos resultantes dessa medida compreende o fato de a extensão da Lei Falcão ter unido "o MDB aos movimentos de base, com a supera- 
ção da defasagem entre os níveis de política formal e política de base" (Moreira Alves, 1984,

p. 197). Outro paradoxo deve-se ao fato de as restrições políticas terem contribuído para desencadear os movimentos populares no final da década de 70 .

Nas eleições de 1978, é evidente que as modificações político-institucionais realizadas pelo governo ajudaram a produzir vitórias na Arena. Contudo "os resultados eleitorais mostravam que nem a Arena tampouco foi indiscutivelmente a vitoriosa" (Kinzo, 1988, p. 201). Nas eleições para o Senado, além do MDB ter vencido na maior parte dos estados do Sudeste e em todos os estados da região Sul, os candidatos da oposição obtiveram votação superior à da Arena nos demais estados, com exceção do Maranhão, Piauí e Mato Grosso. "Isso significava que mesmo nas áreas urbanizadas dos estados menos desenvolvidos do Norte e Nordeste, o MDB havia conquistado expressivo apoio eleitoral. Isto também significava que o reduto eleitoral da Arena se havia reduzido às áreas de base rural, onde o clientelismo e todas as outras formas de controle do voto continuavam a exercer papel decisivo na definição das eleições" (Kinzo, 1988, p. 202).

De forma que a estratégia política do governo, ao se traduzir em consecutivas modificações das regras político-eleitorais, apresentou as seguintes regularidades, como ressaltado por Sallum Jr.: 1) aumentou o peso da representação política das regiões menos desenvolvidas e urbanizadas - mais controláveis pelos partidários do regime -, e 2) valorizou politicamente as elites regionais aliadas (Sallum Jr., 1996, p. 41).

Com efeito, ao tentar construir uma base política que pretendia controlar o desdobramento do processo de abertura e neutralizar, de certa forma, os conflitos de interesses existentes entre os grupos dominantes, o Estado central angariava força política para prosseguir com o seu projeto político.

\section{AS RELAÇÕES ECONÔMICAS DO FEDERALISMO APÓS 1974}

De forma semelhante ao âmbito político-eleitoral, as relações econômicas do federalismo também se revelaram em importante instrumento de controle do processo de distensão, mais especificamente no que se refere à realização do objetivo de integração nacional do projeto do II PND, dentro do qual se sobressaem os instrumentos de ação administrativa e de ação econômica do governo central. Esses instrumentos de ação do governo que conformaram as relações econômicas do federalismo naquele período serão analisados sobre o prisma 1) da articulação com estados e municípios, 2) da estratégia de redirecionamento dos investimentos, e 3) da estratégia da distribuição da renda, todas presentes no projeto do II PND.

É certo que o desenvolvimento regional, subjacente ao chamado "desenvolvimento nacional integrado", já se mostrava como um dos objetivos do governo, como assinalado por Geisel em sua primeira reunião ministerial e na ocasião da aprovação do II PND pelo Congresso, por exemplo. Demais, o projeto do II PND 
também tinha como um de seus objetivos promover uma "nova etapa no esforço de integração nacional" (República Federativa do Brasil, 1974, p. 35).

Entretanto, é a partir da divulgação das metas do II PND em dezembro de 1974, que coincide com o momento em que se verificou a intenção de mudança de ritmo na estratégia de liberalização política, que as relações econômicas do federalismo também adquirem lugar de relevo, ao se traduzirem, juntamente com os mecanismos político-eleitorais, em recurso político na promoção do projeto do governo. Como ressalta Sola, ao assinalar a relação entre os processos de desenvolvimento e de abertura política, "a conjugação e simultaneidade de ambos processos define, em grande parte, a singularidade da experiência brasileira: tanto no que se refere às condições de gestão da crise econômica posterior, quanto a algumas das características do processo de transição política, 'por distensão'” (Sola, 1988, p. 16). Tratou-se, portanto, de um processo de abertura política cum desenvolvimento econômico, em que tanto as relações políticas quanto econômicas - desencadeadas mormente pela ação do governo central — acabam conformando não apenas a trajetória da transição, mas também o processo do federalismo. De forma que o federalismo se revelou, de fato, como eminente instrumento de controle do processo de liberalização controlada.

Como ressaltado alhures (Aguirre e Saddi, 1997), o II PND se refere a um plano politicamente determinado, cuja dinâmica de implementação sofre a influência do processo de liberalização política, pelo fato de o plano econômico se revelar como ferramenta política fundamental para a sustentação do processo de dominaçãolegitimação reivindicado pelo governo vigente. Velasco e Cruz (1980) e Sallum Jr. (1994) também ressaltam que o plano se traduz numa "peça política cuja função é a de costurar as forças heterogêneas que dão suporte político ao regime e que se fazem presentes no interior do aparelho do Estado mediante toda uma teia de relações que as vinculam às diferentes agências, ramos e organismos do mesmo" (Velasco e Cruz, 1980, p. 122).

Há que se lembrar, assim, que, é exatamente pelo fato de as ações sociais e, em particular, as do homem político serem passíveis de racionalização, é que se torna possível efetuar análises que visem a recuperar o real significado dos eventos sociais, sejam eles de ordem política ou econômica. Essas ordens, ou melhor, esferas, como nos ensina Weber (1992), só são passíveis de distinção no âmbito da teoria, uma vez que elas se retroalimentam e se sobrepõem na vida real. No Brasil, essa sobreposição sobrevalorizou-se num momento crítico da História política recente, já que se traduziu num último esforço do governo de institucionalizar uma ordem política autoritária híbrida. De forma que diferentemente da versão oficial (Velloso, 1986 e 1998), e da interpretação de Castro (1985), por exemplo, compreende-se que o II PND não se mostrou na vida real como um plano portador de uma racionalidade econômica no decorrer de sua implementação. ${ }^{6}$

\footnotetext{
${ }^{6}$ E para uma análise do debate sobre a questão da racionalidade econômica do II PND veja os trabalhos de Aguirre e Saddi $(1997,1998)$ e o texto de Velloso (1998).
} 
Cabe assinalar ainda que o intuito primordial do governo não era fomentar as relações econômicas do federalismo, mas continuar promovendo uma modalidade de desenvolvimento econômico que legitimava o regime político desde 1964. Dada a situação política do início de 1975 , a política de desenvolvimento econômico juntamente com os mecanismos político-eleitorais ressaltados — acabaram se revelando em instrumentos essenciais a serem utilizados pelo governo federal no controle da federação na gênese da abertura. De forma que, além de legitimar o processo político, o II PND também pôs à disposição do Estado central os recursos econômicos necessários para angariar apoio e obter controle político no âmbito da Federação brasileira.

De forma que os recursos da economia se traduziram em recursos de apoio e de controle político, logo de cooptação, norteadores das relações do federalismo no princípio da transição. Dentre as políticas do II PND que fomentaram o processo do federalismo destacaram-se algumas derivadas do objetivo de se realizar uma "nova etapa no esforço de integração nacional" (República Federativa do Brasil, 1974, p. 35), qual sejam: 2.1) as políticas subjacentes à articulação com estados e municípios, 2.2) a estratégia de redirecionamento dos investimentos, e 2.3) a estratégia da distribuição da renda regional. Essas medidas serão analisadas com base na inter-relação dos instrumentos de ação econômica e de ações administrativas do governo federal, como verificados no processo de implementação do II PND no período 1975-1979.

\subsection{A Articulação com estados e municípios}

A Secretaria de Articulação com os estados e municípios - SAREM — desempenhou papel essencial no período 1974-1978 como locus de articulação intergovernamental. Foram implementados, no âmbito da SAREM, programas e projetos que objetivavam, por exemplo: "I - deflagrar amplo programa de cooperação técnica, abrangendo todos os Estados e Territórios Federais (...) para a preparação dos programas de aplicação dos recursos do FPE, FPM e FE (...); II - concessão de apoio financeiro aos Estados e Territórios Federais (...); III - elaboração de estudos sobre a situação financeira dos Estados, cujas conclusões confirmam o acerto da decisão superior que propiciou o aumento das transferências federais relativas ao FPE e FPM, consubstanciado na promulgação da emenda Constitucional $n^{\circ} 5 / 75$, que elevou de 12 para $20 \%$ a participação dos estados e municípios nos tributos federais correspondentes ao IR e IPI (...); IV - elaboração de estudos sobre critério de distribuição das transferências federais, o que resultou no Decreto-Lei 1434/75, que permitiu a redistribuição mais justa dos recursos do FPE, beneficiando acentuadamente os estados menos desenvolvidos" (IPEA, 1979, p. 93-5).

Há que se destacar ainda o Programa de Cooperação Técnica, realizado entre 1974 e 1978, o qual procurou inicialmente institucionalizar os Sistemas Estaduais de Planejamento, mediante a definição das funções e estratégias básicas que deveriam integrar um sistema de planejamento. Conforme estratégia definida, a SAREM atuaria diretamente junto às administrações estaduais, e essas com os municípios, 
de forma que ocorreu uma reestruturação no âmbito das administrações estaduais de planejamento. Dentre os mecanismos colocados à disposição das secretarias estaduais de planejamento, destacaram-se: a delegação de poderes para a análise e aprovação dos programas de aplicação do FPM referente aos municípios com população igual ou superior a 25 mil habitantes e o exame de pedidos de operação de crédito com vinculação do FPM.

Além de formular diretrizes do Programa de Cooperação Técnica em todas as etapas e subprogramas, financiou em grande parte tais atividades. Os recursos foram repassados às UFs por meio de convênios e no período 1974-1978 elevaramse a Cr\$ 533,5 milhões. Até o final de 1974 as transferências não tributárias, nas quais se inserem os chamados convênios, "mantinham as características do período anterior: eram pouco expressivas em relação às receitas e despesas governamentais e menos relevantes ainda eram as de caráter negociado. Já em 1975, evidenciaram-se uma forte mudança na sua estrutura interna, apesar de mantidos baixos os indicadores de importância ou dependência dessas transferências" (Afonso, 1989, p. 211, 212).

No entanto, como ressalta Rezende, essa então baixa dependência escondia “o aprofundamento dos laços burocráticos que se desenvolveram em virtude da expansão dos convênios" (Rezende, 1982, p. 499). Essa expansão pode encontrar sua explicação na forma mediante a qual se deu a implementação e desenvolvimento dos sistemas estaduais de planejamento. "Em grande parte dos estados, uma elite burocrática formou-se a partir dos convênios realizados com a SAREM, os quais previam complementação salarial dos dirigentes e técnicos que se encarregavam de organizar o sistema estadual de planejamento (Rezende, 1982, p. 499).

Com efeito, tecnicamente, foi com base nos estudos elaborados pela SAREM que o governo federal "adotou medidas objetivando minimizar os problemas financeiros de cada um dos Estados criando condições para reduzir as dificuldades de seus programas de investimento. Essas providências beneficiaram mais especificamente as regiões que apresentam maior debilidade econômico-financeira, como é o caso do Norte e Nordeste do país" (IPEA, 1979, p. 99). Politicamente, contudo, os resultados dos estudos da SAREM convergiam com o intento do governo federal de buscar apoio das elites políticas regionais após os resultados das eleições de 1974, a fim não apenas de obter apoio político para realizar a distensão, mas também de controlar o processo de institucionalização do regime. $\mathrm{O}$ apoio financeiro do governo federal aos governos estaduais se deu na execução de projetos considerados prioritários. A região Norte absorveu Cr\$ 861,00 milhões; o Nordeste, Cr\$ 6,4 bilhões; o Sudeste, Cr\$ 2,2 bilhões; o Sul, Cr\$ 2,5 bilhões; e o Centro-Oeste, Cr\$ 1,6 bilhões cabendo aos programas federais cerca de Cr\$ 6,0 bilhões.

Como assinala Medeiros, "embora a SAREM objetivasse ser o principal locus das articulações intergovernamentais, as quais seriam orientadas de forma administrativa e burocrática, essa tarefa se tornou paulatinamente muito difícil" (Medeiros, 1986, p. 128). Em especial por que "entre 1974 e 1978 a política deixou os bastidores das arenas burocráticas para se tornar novamente - como o nível de coerção havia relaxado - uma questão aberta e extra-burocrática" (Medeiros, 1986, pp. 128-9). De forma que por terem sido privilegiados os estados menos 
desenvolvidos, os quais estavam sendo incorporados ao arco de aliança política do governo federal, torna-se possível afirmar que as decisões ocorridas no âmbito da SAREM não seguiram exatamente critérios técnico-racionais, na medida em que foram influenciadas pelo processo político de liberalização controlada.

"No plano tributário, a revalorização das elites regionais pelo projeto GolberyGeisel de institucionalização resultou na inversão da tendência que concentrava recursos e decisões nas mãos do Governo federal" (Sallum Jr., 1996, p. 42). A promulgação da Emenda Constitucional no $5 / 75$, a qual elevou a participação dos estados e municípios nos tributos federais (IR e IPI) de 12 para $20 \%$, em acréscimos de $2 \%$ em cada ano, durante o período 1976-1979, contribuiu para melhorar a situação financeira dos Estados e dos municípios. Em decorrência dessa medida, as transferências federais às contas do FPE, FPM e FE cresceram de Cr\$18,3 bilhões, em 1974, para Cr\$24,3 bilhões, em 1976, alcançando Cr\$30,2 bilhões em 1978.

Demais, criou-se ainda uma Reserva Especial para as regiões Norte e Nordeste, por meio do Decreto-Lei no 1434, de 11 de dezembro de 1975. Essa Reserva, distribuída exclusivamente entre os Estados das regiões Norte e Nordeste, proporcionou maior parcela de recursos aos Estados menos desenvolvidos, contando com 10\% dos recursos do FPE nos exercícios de 1976 e 1977 e 20\% em 1978. Em 1976, esses recursos atingiram o montante de Cr\$ 1,1 bilhão, em 1977 alcançaram Cr\$ 1,2 bilhão e em 1978 foi estimado em Cr\$2,3 bilhões o total destinado aos Estados do Norte/Nordeste, além da participação normal do FPE.

Já o Decreto-Lei no 1492, de 6 de dezembro de 1976, transferiu 50\% dos incentivos do ICM para a área do IPI, com a União assumindo esses encargos a partir de 1977. No plano tributário, há que se destacar ainda o incremento das alíquotas internas do principal imposto estadual, o ICM, até atingir $17 \%$ em todos os Estados do País. Ademais, “o Governo Federal, através do DL no 1426 de 2/12/75 assumiu os valores de crédito do ICM existentes em empresas localizadas nos estados do norte e nordeste (...)”. E também “(...) retirou da lista de produtos beneficiados do ICM vários produtos elaborados pelos estados do norte e nordeste" (Lopreato, 1981, p. 139).

Cumpre assinalar ainda a adoção do Decreto $\mathrm{n}^{\circ} 77.565 / 76$, o qual desobrigou os Estados do Norte e Nordeste, bem como o Estado do Espírito Santo, de aplicar percentagem determinada dos recursos do FPE em despesas de capital, podendo, se o desejarem, utilizar integralmente tais recursos em despesas correntes. Essa medida teve significado muito grande para os Estados beneficiados, muito dos quais têm arrecadação própria inferior aos gastos com pessoal.

Como resultado, essas medidas contribuíram para que a participação relativa da região Nordeste aumentasse significativamente no período 1974-1978, passando de 40,8\%, em 1974-1975, para 44,7\% em 1976, e para 54,6\% em 1978. De forma que, de um lado, elas assinalam a preocupação da SAREM em estabelecer critérios de distribuição das rendas públicas para os Estados menos desenvolvidos e, de outro, evidenciam o esforço político do governo federal na obtenção de apoio na realização de seu projeto e na viabilização do controle político da distensão.

Com efeito, essas mudanças nas instituições econômicas que orientaram as 
relações do federalismo resultaram em maior disponibilidade de recursos econômicos para os Estados que se encontravam à margem das relações políticas dominantes no período militar anterior. Trata-se de mudanças que se deram em meio às "situações" de incerteza acarretadas pelo processo político-eleitoral, sobretudo no pós-1974.

A liberalização política permitiu, portanto, a abertura de um espaço para que Estados e municípios passassem a criticar o sistema fiscal centralizado e a demandar melhor divisão do bolo tributário. "Há aqui um amplo espaço para negociação que ocorre sem maiores atropelos, mesmo com um Congresso submisso, porque não há nem enfrentamento com o regime nem choque de forças sociais (...)". Uma vez que o equacionamento dos problemas “(...) depende apenas de o Poder Central se dispor a atenuar o centralismo econômico e injetar novo alento ao federalismo que se tornara uma ficção” (Oliveira, 1995, p. 65).

\subsection{Empréstimos a Estados e municípios}

No que se refere às operações de crédito a Estados e municípios, cabia à Secretaria de Planejamento da Presidência da República (SEPLAN), como órgão de assessoramento direto ao presidente da República, manifestar-se a respeito da viabilidade e compatibilidade do empréstimo com os planos nacionais de desenvolvimento nos pedidos de empréstimos ou acordos externos, de interesse dos Estados, do Distrito Federal e dos municípios, e nas operações de créditos internos, quando se oferecem como garantia recursos do Fundo de Participação (FPE e FPM). Nestes casos, com o advento da Resolução do Senado Federal no 62, de outubro de 1975, o Banco Central passou a realizar os estudos correspondentes ao endividamento global do mutuário em potencial, mas cabendo à SEPLAN e, mais especificamente, ao Executivo Federal, pronunciar-se quanto ao nível de comprometimento dos fundos citados.

Essa resolução do Senado também modificou sensivelmente os limites a que eram subordinadas as operações de crédito de Estados e municípios. Rezende e Afonso mostram, em relação a esses limites, que pelo fato de eles não "manterem as aberturas ou exceções que a regulamentação anterior propiciava, a maioria das unidades governamentais excedia os tetos máximos, dependendo, para novas operações, de autorização expressa do Senado (Rezende e Afonso, 1988, p. 8). Como resultado, esses limites "foram alterados por iniciativa do Poder Executivo, pela Resolução no 93/76 (...)". Essas mudanças na regulamentação de crédito "foram justificadas com a intenção de se adotar critérios mais flexíveis para o controle da dívida pública consolidada interna, tendo em vista as exigências da conjuntura e as próprias condições econômico-financeiras dos estados e municípios" (Afonso, 1989, p. 233).

A princípio, os pedidos de empréstimos por parte das unidades da Federação são submetidos a análises baseadas em critérios técnicos. Contudo, a regulamentação vigente não considerou, por exemplo, um dos mais importantes requisitos para empréstimo, como a capacidade de endividamento e de pagamento. Em espe- 
cial porque se instituiu um sistema de crédito o qual "envolve o poder discricionário concentrado no Executivo e Senado Federal, bem como a limitação da autonomia estadual e local pela vinculação na aplicação de recursos (...)". De forma que “(...) uma avaliação casuística, influenciada por fatores políticos, deve importar mais nas decisões sobre as operações não controladas” (Rezende e Afonso, 1988, p. 15).

No que se refere à perda de autonomia ou incremento da dependência financeira por parte das unidades da Federação, os empréstimos internos mostravamse amarrados a determinados projetos que exigem a comprovação do uso da verba. No entanto, essa comprovação do destino do crédito "não é válida para o crédito externo, o que na verdade, ao contrário de empecilho, representa um estímulo ao endividamento pelo controle relativamente mais flexível” (Rezende e Afonso, 1988, p.15).

O governo federal também adotou medidas que visavam ao desenvolvimento de setores definidos como estratégicos para a economia nacional. Com base na Resolução no 394, de 3 de novembro de 1976, que veio a reformular e consolidar a anterior, os Bancos Estaduais de Desenvolvimento poderiam operar com depósitos a prazo fixo, realizar intermediação de empréstimos e financiamentos obtidos no país e no exterior, emitir ou endossar células hipotecárias de crédito rural, realizar investimentos e operações de arrendamento mercantil e prestar garantias. $\mathrm{O}$ saldo dos recursos movimentados pelos 12 bancos estaduais de desenvolvimento elevouse de Cr\$ 5.157 milhões em 1973 para Cr\$ 66.460 milhões em junho de 1978, dos quais Cr\$56.261 milhões referem-se a terceiros. É importante notar que o incremento das obrigações contraídas com terceiros na configuração dos recursos dos BEDs evoluiu de 77,7\% em 1973 para 84,7\% em 1978, principalmente em virtude dos repasses das instituições financeiras oficiais que evoluíram de Cr\$1,970 milhões para Cr\$ 50.004 milhões, no período considerado. Dentre as principais instituições oficiais repassadoras de recursos para os BEDs destacam-se o BNDE, a FINAME, o Banco Central e o BNH, com 28,3\%, 20,9\%, 12,7\% e 6,9\% respectivamente, do total dos recursos existentes em junho de 1978 (Cr\$ 66,5 milhões).

Há que se assinalar ainda que o conjunto dos Bancos Estaduais de Desenvolvimento foi ampliado nesse período com a criação dos Bancos de Desenvolvimento dos Estados de Santa Catarina e do Rio Grande do Sul em 1975 e do Banco do Estado de Goiás em 1976. Cabe ressaltar que após consecutivas alterações nas regulamentações de crédito a Estados e municípios, principalmente no que se refere aos limites de crédito, "ora restringindo, ora aumentando a rolagem das dívidas, o desdobramento recente desse processo foi o aumento da dependência de estados e municípios em relação ao Tesouro Nacional” (Rezende e Afonso, 1988, p. 27). De forma que, como ressalta Sallum Jr., "é verdade que a dependência se refez pela via financeira, na medida em que empréstimos controlados pela União - para saneamento, habitação, etc. - reintroduziram os controles sobre os gastos estaduais. A diferença é que, nesse caso, a dependência resultava de uma opção política voluntária” (Sallum Jr., 1996, p. 42).

Essa dependência financeira em relação à União se traduziu em expectativa de insolvência da dívida nas décadas seguintes, uma vez que o processo inflacionário contribuiu para que o saldo da dívida, bem como os encargos devidos a cada ano, 
crescessem a taxas superiores à expansão da arrecadação tributária e operacional da própria, daí o contínuo aumento no grau de vulnerabilidade financeira dos governos mais endividados.

\subsection{A Estratégia da Distribuição da Renda Regional}

Também foi partir de 1975, quando se iniciou a implementação do II PND, que o governo Geisel instituiu três relevantes programas de desenvolvimento regional: o POLAMAZÔNIA, o POLONORDESTE e o POLOCENTRO, os quais mostraram-se como uma das variáveis caracterizadoras das relações do federalismo no período. Esses programas "fundamentam-se na concepção de áreas integradas, espacialmente descontínuas, onde se concentram os esforços de implantação ou consolidação da infra-estrutura, de aproveitamento das potencialidades naturais existentes, de apoio às atividades diretamente produtivas, agropecuárias, minerais ou agroindustriais (IPEA, 1979, p. 130). Mediante a implementação do programa POLONORDESTE, por exemplo, "a segunda linha de exportação de minério de ferro - Carajás - a maior siderúrgica seria construída em Itaqui, Maranhão. A química de base e o esforço de prospecção de petróleo se desenvolveriam prioritariamente na plataforma litorânea nordestina e os complexos químicos de base seriam de soda-cloro em Alagoas, petroquímica na Bahia e no Rio Grande do Sul, fertilizantes potássio em Sergipe, cobre no interior da Bahia, fosfato no interior de Minas" (Lessa, 1977, p. 60). Até março de 1979 o governo investiu Cr\$27,9 bilhões no total, com esses programas de desenvolvimento. Sendo que, nesse total, o POLAMAZÔNIA participou com Cr\$ 7,6 bilhões (27,24\%), o POLONORDESTE com Cr\$16,2 bilhões $(58,06 \%)$, e o POLOCENTRO com Cr\$ 4,1 bilhões (14,70\%).

Cumpre ressaltar ainda que a estratégia de institucionalização do regime tentou envolver na sua órbita não só as elites políticas regionais aliadas, mas também grupos econômicos de importância local que lhes pudessem dar sustentação. Como mostra o fato de o governo federal também ter procurado viabilizar os projetos nas áreas da SUDENE e Espírito Santo desde 1974, prorrogando os prazos das isenções do Imposto de Renda para os empreendimentos na área de atuação da SUDENE e Espírito Santo. Como resultante da política de desenvolvimento regional do II PND, “o que se assistiu, no período, foi a convergência da renda 'per capta' das regiões no Brasil em torno da média nacional, com a renda das regiões menos desenvolvidas crescendo mais intensamente que a das regiões de renda por habitante maior que a média do país" (Guimarães Neto, 1995, p. 26).

Contudo, esse processo de incorporação de novos grupos à aliança desenvolvimentista do Estado não ficou imune ao conflito próprio da vida política. Mais especificamente pelo fato de as reivindicações desse novo grupo se mostrarem inconsistentes com: "a) a necessidade de realização de lucro, que gera uma fonte autônoma de alimentação da inflação, dado o estágio do ciclo de investimentos recentes (excessivo endividamento das estatais e capacidade ociosa no setor de bens de capital); b) os interesses da indústria do Sul, contrária à redução dos níveis de proteção da indústria instalada pelos projetos de substituição de importações anteriores; c) a sobre- 
valorização cambial, instrumento tradicional usado pelo Estado para introduzir o investimento industrial, retira competitividade internacional de todos os setores exportadores; d) a escassez de recursos gerada pela necessidade do financiamento da dívida pública interna. É bom lembrar que a forma tradicional de cooptação das lideranças políticas do Norte-Nordeste era a que trocava incentivos fiscais regionais e sua participação nos investimentos do Sul, utilizando-se dos fundos fiscais (BNH e PIS/PASEP), por apoio parlamentar" (Dias e Aguirre, 1992, p. 89).

Cumpre ressaltar que a política de desenvolvimento regional de Geisel evidencia que os primeiros passos para a descentralização de recursos entre as unidades da federação ocorreram em meio a uma situação em que liberalização política se combinava com a manutenção do crescimento da economia. Num período em que o processo do federalismo se deu, tanto no âmbito da economia, quanto no da política, sem que o poder central perdesse as rédeas de seu controle.

\section{O FEDERALISMO NO GOVERNO GEISEL: O PRINCÍPIO DE UM FEDERALISMO DE IMPASSE}

As ações do governo federal subjacentes às relações políticas e econômicas do federalismo, no pós-1974, provocaram mudanças no contínuo centralização-descentralização, em direção a uma maior descentralização das relações federativas. Tratou-se, mais especificamente, de mudanças caracterizadas pela renovação, ou melhor, pela ampliação da coalizão socioeconômica de apoio ao governo e pela redefinição das regras político-institucionais nesse novo período do regime militar. Essa redefinição política se deu mediante 1) o aumento do peso da representação política das regiões menos desenvolvidas e urbanizadas - mais controláveis pelos partidários do regime -, e 2) o incremento da valorização política das elites regionais aliadas. Contudo, assevera-se que, nos anos Geisel, esse processo de mudança continuava a apresentar elementos de continuidade em relação ao período anterior, tanto no que se refere ao padrão de dominação — apesar da ampliação do arco de relações sociais dominantes inseridas no Estado - , quanto no que diz respeito à manutenção de uma ordem política autoritária híbrida, embora mais liberalizante.

As transformações verificadas na forma de organizar o poder, desencadeadas pela ação do Estado central, ocorreram em meio a um ambiente de incertezas, no qual os recursos da política e da economia se complementaram como instrumentos políticos para dar continuidade e sustentação às relações de dominação-legitimação, na qual se inserem às do federalismo. Cabe assinalar ainda que as mudanças nas instituições políticas e econômicas norteadoras das relações do federalismo no governo Geisel não apenas se retroalimentaram e se sobrepuseram no princípio da distensão, mas também continuaram a influenciar esse processo no decorrer da transição política.

Como observado, o período Geisel foi marcado por uma descentralização relativa de recursos da esfera da União para Estados e municípios. No entanto, apesar de essa descentralização ter fornecido maior volume de recursos às unidades 
subnacionais de governo, também ampliou o grau de dependência destas em relação à União, de forma que os resultados da distensão dos anos Geisel mostram-se paradoxais no que diz respeito à descentralização, na medida em que a ampliação do espaço de liberdade política, via eleições, se traduziu em acréscimo da dependência financeira das unidades federativas em relação ao governo federal.

Esse processo de descentralização encerra outro paradoxo. Ao distribuir poder político para os Estados no intuito de controlar o processo de distensão, o Executivo federal dá condições políticas para que as unidades federativas revertam o quadro de dependência financeira nos anos seguintes, no decorrer da transição política. A ação do governo federal acaba produzindo um resultado não intencionado: o Executivo federal perde o controle do processo de transição política.

Paradoxalmente o governo Geisel semeou o terreno para que as elites políticas regionais, mais especificamente os governadores, pudessem se sobressair como verdadeiros chefes políticos estaduais no princípio da transição. Porquanto o processo de distensão controlada via eleições acabou produzindo o aumento da dependência dos militares em relação ao poder do governo no Legislativo e em relação às elites políticas no nível estadual. Há que se ressaltar ainda que o aumento da representação dos Estados menos desenvolvidos mostrou-se contraditório à regra democrática básica - "um homem, um voto" - e à própria Constituição, que estabelece a igualdade de todos os cidadãos. Esta distorção foi agravada com a Constituição de 1988, que aumentou o piso de representação dos Estados menores e transformou territórios em Estados.

Os efeitos desse paradoxo de resultado também vieram à tona nos trabalhos em matéria tributária da Assembléia Nacional Constituinte. O capítulo referente ao sistema tributário nacional da Constituição de 1988 estabeleceu a descentralização de receitas em favor dos Estados e municípios. Concedeu-lhes competências tributárias exclusivas e autonomia para legislar, coletar, controlar os gastos, podendo fixar as alíquotas dos impostos. A Constituição também incrementou a participação dos governos subnacionais na arrecadação do governo federal, por meio do aumento das transferências dos fundos de participação. Estabeleceu a municipalização da oferta de serviços sociais e a responsabilidade compartilhada das três esferas no atendimento desses serviços, como saúde, educação e assistência social. No entanto, o texto constitucional não firmou a redistribuição das competências entre as esferas de governo. "O fortalecimento financeiro das esferas subnacionais, sobretudo dos governos municipais, e o correspondente enfraquecimento da União, sinalizavam, entretanto, diante da recusa do Congresso Constituinte a aprovar um texto claro e pactuado de descentralização de encargos, o surgimento de problemas potenciais nas relações entre as unidades da Federação e, assim, no atendimento das demandas sociais" (Oliveira e Biasoto, 1999, p. 20).

Ressalta-se, portanto, que o processo político federativo dos anos Geisel criou a base política para que se formasse um tipo de "federalismo de impasse"

\footnotetext{
${ }^{7}$ Este termo foi sugerido por Basilia Aguirre na defesa de mestrado da autora.
} 
princípio da democratização política brasileira. Este impasse refere-se à inexistência de um acordo pactuado entre as partes sobre a divisão das responsabilidades que se encontram "compartilhadas" na Constituição.

A despeito disso, Estados e municípios, estes, sobretudo, passam a arcar com a responsabilidade de efetuar políticas sociais. Isso ocorreu porque a própria descentralização de receitas contribuiu para a descentralização das responsabilidades no atendimento das demandas sociais em meio à democratização política. No entanto, o processo de descentralização de recursos fiscais para Estados e municípios esconde problemas que podem comprometer seu aprofundamento, dado as distintas realidades dos municípios brasileiros, que tiveram seu número incrementado ${ }^{8}$ na recente democratização. Como assinalado pela literatura de finanças públicas e/ou descentralização, esse processo encontra-se dificultado pela ausência de um projeto pactuado entre os entes federativos.

Esse impasse também pode ser compreendido quando se verifica a influência exercida pelas decisões da política sobre a condução do processo político e econômico. Ao longo da democratização alguns temas, como a reforma política e tributária, mostraram-se inegociáveis no Congresso nacional e, assim, nem sequer ou com pouco êxito chegaram a ocupar a agenda do País. No âmbito político, os Estados menos populosos - privilegiados pela representação não proporcional — se opõem a medidas que objetivam corrigir a distorção representativa no Congresso. $\mathrm{Na}$ esfera econômica, as bancadas regionais desses Estados super-representados possuem peso determinante nas decisões sobre alocação de recursos e eventual incidência dos custos de um ajustamento. A revisão constitucional de 1993/94, por exemplo, não aprovou nenhum dos itens que pretendiam modificar a estrutura tributária e fiscal.

Nos anos 80 e, sobretudo, no início dos anos 90, o "governo federal, mesmo administrando uma fração menor do dispêndio total, passou a ser cada vez mais cobrado pela adoção de um plano de estabilização que finalmente desse conta do problema da altíssima inflação, o que idealmente deveria ser acompanhado de um estrito controle do gasto público como um todo - e não apenas da parcela do governo federal" (Giambiagi e Além, 1999, p. 268). Diferentemente dos anos anteriores, a prática tradicional de transferir as dificuldades financeiras estaduais e municipais para a União mostrava-se nociva ao processo de dominação vigente. Em meados dos anos 90 o governo federal utilizava-se de expedientes que independiam da aprovação do Congresso, e/ou negociava diretamente com as bancadas e/ ou políticos, ao agir não apenas em reação à perda de recursos, mas também no intuito de controlar o déficit público dos governos subnacionais. Diminuiu as transferências não constitucionais para Estados e municípios, estabeleceu restrições de crédito para as esferas subnacionais, criou tributos e aumentou a alíquota de impostos não compartilhados com as demais esferas, por exemplo. Essas medidas, entre outras, desencadearam as tensões federativas dos últimos anos.

Convém ressaltar que este tipo de resposta do governo federal afeta de forma

\footnotetext{
${ }^{8}$ Entre 1980 e 1996 o número de municípios brasileiros aumentou 33\%.
} 
diferenciada os Estados e os municípios. Estes últimos são os agentes mais importantes da recente descentralização dos serviços públicos, por terem assumido as responsabilidades dos governos estaduais e federal e por manterem níveis de gastos e de investimentos essenciais para a oferta dos serviços públicos. Levando-se em conta as distintas dificuldades financeiras enfrentadas pelos municípios, a ausência de um projeto pactuado entre as esferas de governo - o qual vise a uma clara distribuição de responsabilidades, procurando também redefinir suas fontes de financiamento -, dificulta o andamento da descentralização ou mesmo se mostra como um impasse para esse processo em alguns casos.

$\mathrm{O}$ "federalismo de impasse" originado no princípio da distensão política brasileira deixa uma grande lição para economistas e cientistas políticos: as relações políticas e econômicas se complementam na definição e reconfiguração do arranjo federativo, sendo que a política determina de forma acentuada o destino das relações econômicas subjacentes ao federalismo. Pode-se inferir aqui, como já mostrou a História, que a reforma tributária não ocorrerá sem que antes se efetue uma reforma política. No entanto, a realidade nos ensina, mais uma vez, que o federalismo brasileiro, em especial no que se refere à continuidade da descentralização, possivelmente continuará a ser definido e redefinido por soluções políticas criativas e às vezes imediatistas, encontradas, passo a passo, nos períodos em que os conflitos vierem à tona e se constituírem em "situações" de impasse para o processo político.

\section{REFERÊNCIAS BIBLIOGRÁFICAS}

ABRUCIO, Fernando Luís (1994). “Os Barões da Federação: O Poder dos Governadores no Brasil PósAutoritário”. Tese de Mestrado DCP/USP, São Paulo.

AFONSO, José Roberto Rodrigues (1989). "Evolução das Relações Inter-governamentais no Brasil entre 1968/1988: Transferências e Endividamento”. Rio de Janeiro. Dissertação de Mestrado, Instituto de Economia Industrial da UFRJ.

AGUIRRE, Basilia e SADDI, Fabiana (1997). “Uma Alternativa de Interpretação do II PND”. Revista de Economia Política, vol. 17, $\mathrm{n}^{\circ} 4$ (68), out-dez.

AGUIRRE, Basilia e SADDI, Fabiana (1998). "Fantasia política ou política da fantasia?”. Revista de Economia Política, vol. 18, no 2 (70), 1998, p. 145-7.

BRITTO, Luiz Navarro (1980). “As Eleições de 1978”. Revista Brasileira de Estudos Políticos, n 51, julho.

CASTRO, Antonio Barros (1985) “Ajustamento x Transformação: A Economia Brasileira de 1974 a 1984. In: CASTRO, A.B. e F.E.P. SOUZA (1985) A Economia Brasileira em Marcha Forçada, $2^{a}$ ed. São Paulo: Paz e Terra.

COHN, Gabriel (1979). Crítica e Resignação: Fundamentos da Sociologia de Max Weber. T. A. Queiroz Editor, São Paulo.

DIAS, G. L. da S. e B. M. B. AGUIRRE (1992). “Crise Político-Econômica: As Raízes do Impasse”, Estudos Avançados, 6 (14), 1992.

GIAMBIAGI, Fabio \& ALÉM, Ana Cláudia (1999). Finanças Públicas: Teoria e Prática. Rio de Janeiro, Editora Campus.

GUIMARÃES NETO, Leonardo (1995). “Dinâmica Recente das Economias Regionais Brasileiras”. In: São Paulo em Perspectiva, São Paulo, vol.9, jun-set.

IPEA (1979). Realizações do Governo Geisel (1974-1978), 6 vols, Brasília, Relatório de Pesquisa, Instituto de Planejamento Econômico e Social. 
KINZO, Maria D’Alva Gil (1988). Oposição e Autoritarismo: gênese e trajetória do MDB (1966/1979). IDESP / Vértice, São Paulo.

KLEIN, Lúcia e FIGUEIREDO, Marcus (1978). Legitimidade e Coação no Brasil Pós-1964. Rio de Janeiro, Forense Universitária.

LAMOUNIER, Bolívar (1988). “O ‘Brasil Autoritário’ revisitado: o impacto das eleições sobre a abertura”, in STEPAN, Alfred, org., (1988) Democratizando o Brasil. São Paulo, Paz e Terra, pp. 83134.

LESSA, Carlos (1977). “Visão Crítica sobre o II Plano Nacional de Desenvolvimento”, Revista Tibiriçá, Ano II, n 6, jan-mar.

LOPREATO, Luiz C. (1981). Evolução da participação estadual na distribuição institucional de renda. Campinas, Dissertação de Mestrado, IFCH — UNICAMP.

MATHIAS, Suzeley Kalil (1995). Distensão no Brasil: O Projeto Militar (1973-1979). Campinas, Papirus.

MEDEIROS, Antônio C. (1986). Politics and Intergovernamental Relations in Brazil 1964-1982. New York e London, Garland Publishing.

MOREIRA ALVES, Maria Helena (1984). Estado e Oposição no Brasil (1964-1984). Petrópolis, Editora Vozes.

O’DONNEL, Guillermo e SCHMITTER, Phillipe (1988). Transições do Regime Autoritário: Primeiras Conclusões. São Paulo, Vértice. O’DONNEL, Guillermo e SCHMITTER, Phillipe (1988). Transições do Regime Autoritário: Primeiras Conclusões. São Paulo, Vértice.

OLIVEIRA, Fabrício Augusto (1995). Autoritarismo e Crise Fiscal no Brasil (1964-1984). São Paulo, Editora Hucitec.

OLIVEIRA, Fabrício Augusto e BIASOTO, Geraldo (1999). "Descentralização das Políticas Sociais no Brasil”, in ARRETCHE, Marta e RODRIGUEZ, Vicente (1999). Descentralização das Políticas Sociais no Brasil. São Paulo, Fapesp/IPEA/Fundap.

REPÚBLICA FEDERATIVA DO BRASIL (1974). Projeto do II Plano Nacional de Desenvolvimento (1975 - 1979), Brasília.

REZENDE, Fernando (1982). "Autonomia política e dependência financeira: uma análise das transformações recentes nas relações inter-governamentais e seus reflexos sobre a situação financeira dos estados". Pesquisa e Planejamento Econômico, Rio de Janeiro, 12 (2), pp. 489-540.

REZENDE, Fernando e AFONSO, José Roberto (1988). “O (Des) Controle do Endividamento de Estados e Municípios: análise crítica das normas vigentes e propostas de reforma”. Texto para Discussão Interna do IPEA, n ${ }^{\circ} 132$, Rio de Janeiro.

SALLUM JÚNIOR, Brasílio (1994). “Transição Política e Crise de Estado”. Lua Nova, no 32, CEDEC, São Paulo, 1994.

SALLUM JÚNIOR, Brasílio (1996). "Federação, Autoritarismo e Democratização”, in Tempo Social, Rev. de Sociologia da USP, vol 8, n 2, pp. 27-52.

SANTOS, Wanderley Guilherme (1978) Poder e Política: Crônica do Autoritarismo Brasileiro. Rio de Janeiro, Forense Universitária.

SOLA, Lourdes (1988). "Choque Heterodoxo e Transição Democrática sem Ruptura: Uma Abordagem Transdisciplinar”, in SOLA, Lourdes, org. (1988) O Estado da Transição: Política e Economia na Nova República, São Paulo, Vértice.

VELASCO E CRUZ, Sebastião C. (1980). “Estado e Planejamento no Brasil - 1974/1976 (Notas sobre um trabalho de Carlos Lessa)". Estudos Cebrap, n 27.

VELlOSO, João Paulo dos Reis (1986). O Último Trem para Paris. Rio de Janeiro: Nova Fronteira.

VELLOSO, João Paulo dos Reis (1998). "Fantasia política". Revista de Economia Política, vol. 18, nº 2 (70), abr-jun.

WEBER, Max (1968) Economy and Society: An Outline of Interpretive Sociology. ROTH, G. e C. WITTICH, eds., 3 vols. New York: Bedminster Press, 1968.

WEBER, Max (1992). Essais sur la Théorie de la Science. Paris, Plon. 